\title{
A DINÂMICA CLIMÁTICA E A VARIABILIDADE DA PRECIPITAÇÃO NO ESTADO DE SÃO PAULO: O ÍNDICE DE PRECIPITAÇÃO E O ÍNDICE DE PRECIPITAÇÃO CONCENTRADA
}

\author{
Beatriz Siqueira \\ Universidade Estadual de Campinas, Instituto de Geociências, Campinas, SP, Brasil \\ biasiqueira@ige.unicamp.br \\ Jonas Teixeira Nery \\ Universidade Estadual Paulista, campus de Ourinhos, SP, Brasil \\ jonas@ourinhos.unesp.br
}

\begin{abstract}
RESUMO
O presente trabalho promove uma estimativa sobre a variabilidade da precipitação no estado de São Paulo associada à dinâmica climática atuante, através de índices de quantificação diária e mensal da precipitação. Esses índices são estatísticos e podem ser aplicados à Climatologia em análises que envolvam a quantificação da precipitação. Os índices têm se mostrado ferramentas eficientes não só na quantificação, como na previsibilidade de eventos extremos de chuva. O estado de São Paulo vem sofrendo com um intenso e desordenado processo de urbanização desde meados do século XIX e possui um importante núcleo urbano a nível mundial, a cidade de São Paulo, que sofre com situações de enchentes e inundações quando esses eventos acontecem. O estado apresentou um contraste marcante entre as duas quantificações, com concentração diária maior no centro e extremo sul do território, áreas estas que concentraram as menores quantificações mensais. Tal fato possibilitou identificar a ocorrência cada vez mais frequente de precipitação intensa concentrada em poucos dias, uma característica diretamente atrelada ao processo de urbanização e às mudanças climáticas que ele acarreta.
\end{abstract}

Palavras-chave: Dinâmica climática. Variabilidade. Índices de concentração.

\section{THE CLIMATE DYNAMICS AND THE VARIABILITY OF PRECIPITATION IN THE STATE OF SÃO PAULO: THE PRECIPITATION INDEX AND THE CONCENTRATED PRECIPITATION INDEX}

\begin{abstract}
The present work promotes an estimation of the variability of precipitation in the state of São Paulo associated to the active climatic dynamics, through daily and monthly precipitation quantification indices. These indices are statistical and can be applied to Climatology in analyzes that involve the quantification of precipitation. and has been shown to be efficient tools not only in the quantification, but also in the predictability of extreme rainfall events. The state of São Paulo has been suffering from an intense and disorderly urbanization process since the middle of the 19th century and has an important urban center worldwide, the city of São Paulo, which suffers from flood and flood situations when these events occur. The state presented a marked contrast between the two quantifications, with a higher daily concentration in the center and southern end of the territory, which concentrated the smallest monthly quantifications. and monthly quantification in the same area. This fact made it possible to identify the increasingly frequent occurrence of intense precipitation concentrated in a few days, a characteristic directly linked to the urbanization process and the climate changes it entails.
\end{abstract}

Keywords: Climatic dynamics. Variability. Concentration indexes. 


\section{INTRODUÇÃO}

A distribuição espacial e temporal da precipitação na Região Sudeste do Brasil se configura como seu traço mais marcante. Esse fator ambiental de grande importância na região influencia os aspectos biológicos e socioeconômicos da mesma (NUNES et al. 2009a).

Para Nimer (1989) o caráter de transição climática da Região Sudeste se inclina mais para os climas tropicais do que para os temperados: a marcha estacional da precipitação, determinando uma estação muito chuvosa e outra seca, constitui sua característica mais importante. Este caráter de transição aparece refletido em todos os aspectos de seu regime térmico e estes, por sua vez, exprimem a maior ou menor influência marítima do relevo, da latitude e dos sistemas de circulação atmosférica.

A orografia determina o predomínio de temperaturas amenas na Região Sudeste do Brasil e, algumas vezes, mínimas muito baixas, o que permite compreender porque essa região do país, embora situada em sua quase totalidade na zona intertropical, possui extenso território com médias mensais muito baixas no inverno em relação às que se verificam em outras regiões tropicais do país (NIMER, 1989).

A topografia acidentada confere à Região Sudeste do país, os maiores contrastes morfológicos do Brasil: relevo com predomínio de 500 a 800 metros em São Paulo e 500 a 1200 metros em Minas Gerais e a presença de vales muito amplos e rebaixados, como o do São Francisco, Jequitinhonha, Doce, Paraíba do Sul, Paranaíba, Grande e Paraná. Sobre estas superfícies estão numerosas serras onde são comuns níveis entre 1200 e 1800 metros, como na Serra do Espinhaço, da Mantiqueira e do Mar (NIMER, 1989).

Além dos fatores estáticos, é importante obter conhecimento e estruturar análises a respeito dos fatores dinâmicos, ou seja, dos mecanismos atmosféricos. Ambos os fatores, estáticos e dinâmicos interagem entre si provocando alterações nos modos de vida dos indivíduos. O sul da Região Sudeste do Brasil, onde localiza-se o estado de São Paulo, é afetado pela maioria dos sistemas sinóticos que atingem a Região Sul do país, com algumas ressalvas em termos de intensidade e sazonalidade dos sistemas (NERY et al. 2004). Um exemplo desses sistemas sinóticos são os cavados invertidos, que provocam condições de tempo moderado no estado de São Paulo, especialmente durante o inverno (FERNANDES et al. 1994).

Os índices pluviométricos exibidos pelo estado variam, desde quotas excepcionalmente altas como as apresentadas pelas encostas da Serra do Mar (2000 mm a $4500 \mathrm{~mm}$ anuais), até índices moderados, em certos trechos da Depressão Periférica Paulista (1000 a $1100 \mathrm{~mm}$ anuais). No Litoral Sul do estado, como em trechos limitados do Litoral Norte, do extremo noroeste, centro-oeste e quase todo o Planalto Atlântico, apresentam precipitações entre 1500 e 1900 mm anuais (NERY et al. 2004).

No que tange à classificação climática, o estado de São Paulo, seguindo a classificação de Köppen, apresenta climas do tipo Cwa, Cwb, Cfa e Cfb. O tipo Cwa abrange as porções centrais e setentrionais da Depressão Periférica paulista, assim como do Noroeste, Centro, Oeste e extremo Oeste do referido estado. A modalidade Cwb de Köppen - espécie de clima temperado quente com inverno relativamente seco e temperatura média dos meses mais quentes inferior a $22^{\circ} \mathrm{C}$ possui uma área de extensão bem mais restrita e descontínua no território paulista. O tipo climático Cfa, da classificação da Köppen, que é um clima temperado quente úmido, sem estiagem, com temperatura média do mês mais quente inferior a $22{ }^{\circ} \mathrm{C}$ e $\mathrm{Cfb}$, modalidade paulista de clima temperado sem estiagem, com temperatura de verão inferior a $22^{\circ} \mathrm{C}$ (NERY et al. 2004).

De acordo com Nery et al. (2004) a distribuição dos tipos climáticos no território paulista é bastante sugestiva, uma vez que os climas tropicais constantemente úmidos $(A f)$ se restringem a uma faixa limitada do litoral paulista, os climas tropicais de Verão úmido e Inverno seco $(A w)$ têm sua área de domínio numa larga zona do extremo noroeste e norte do Estado.

Essa classificação climática permite estruturar considerações a respeito do desenvolvimento de atividades econômicas no Estado de São Paulo, como o cultivo de banana, no clima Af e a criação de pastagens tropicais no tipo $A w$, além de algumas lavouras relacionadas a solos excepcionalmente bons. No tipo Cwa existem grandes manchas de terras-roxas onde se desenvolveram as principais lavouras de café do Estado (NERY et al. 2004).

O estado de São Paulo faz limite com os estados de Minas Gerais (N e NE), Rio de Janeiro (NE), oceano Atlântico (L), Paraná (S) e Mato Grosso do Sul (O). Em 2016, o referido estado possuía aproximadamente 44.749.699 habitantes, distribuídos em 248.219.627 km², em 645 municípios. Desses quase 45 milhões de habitantes, aproximadamente 22 milhões estão concentrados na Região Metropolitana de São Paulo (IBGE, 2017)

$\begin{array}{llllll}\text { Caminhos de Geografia } & \text { Uberlândia - MG } & \text { v. 19, n. } 67 & \text { Set/2018 } & \text { p. 99-108 } & \text { Página } 100\end{array}$


A elevada densidade demográfica no território paulista está atrelada ao expressivo processo de urbanização pelo qual o estado passa desde meados do século XIX. Esse processo acarreta em uma intensa e desordenada ocupação do solo que tem como consequência sérios problemas ambientais e na qualidade de vida das pessoas, especialmente quando eventos extremos de precipitação se associam a esse fator.

Diante dessas considerações, será estruturado neste trabalho um estudo a respeito da variabilidade da precipitação no estado de São Paulo, associada à dinâmica climática e à atuação de sistemas sinóticos. A precipitação será quantificada através de índices estatísticos aplicados à Climatologia: o índice de Concentração (IC) e o Índice de Precipitação Concentrada (IPC), de quantificações diária e mensal, respectivamente.

O objetivo é promover uma associação explicativa e direta entre a distribuição e variabilidade da precipitação e a dinâmica climática atuante, com a finalidade de auxiliar em outros estudos e pesquisas que possuam o estado de São Paulo como tema central, visto que o clima interage com inúmeras variáveis possíveis de análise, como a vegetação, o solo, o relevo, o uso e a ocupação do solo e os modos de vida da população em geral.

\section{METODOLOGIA}

Neste trabalho foram utilizadas 60 estações pluviométricas (Figura 1) da Agência Nacional de Águas (ANA) obedecendo à lógica de distribuição espacial no estado de São Paulo, objetivando resultados precisos e consistentes, em um período que compreende os anos de 1970 a 2010. No site da ANA as estações podem ser obtidas pela plataforma HIDROWEB.

Figura 1: Localização das estações pluviométricas.

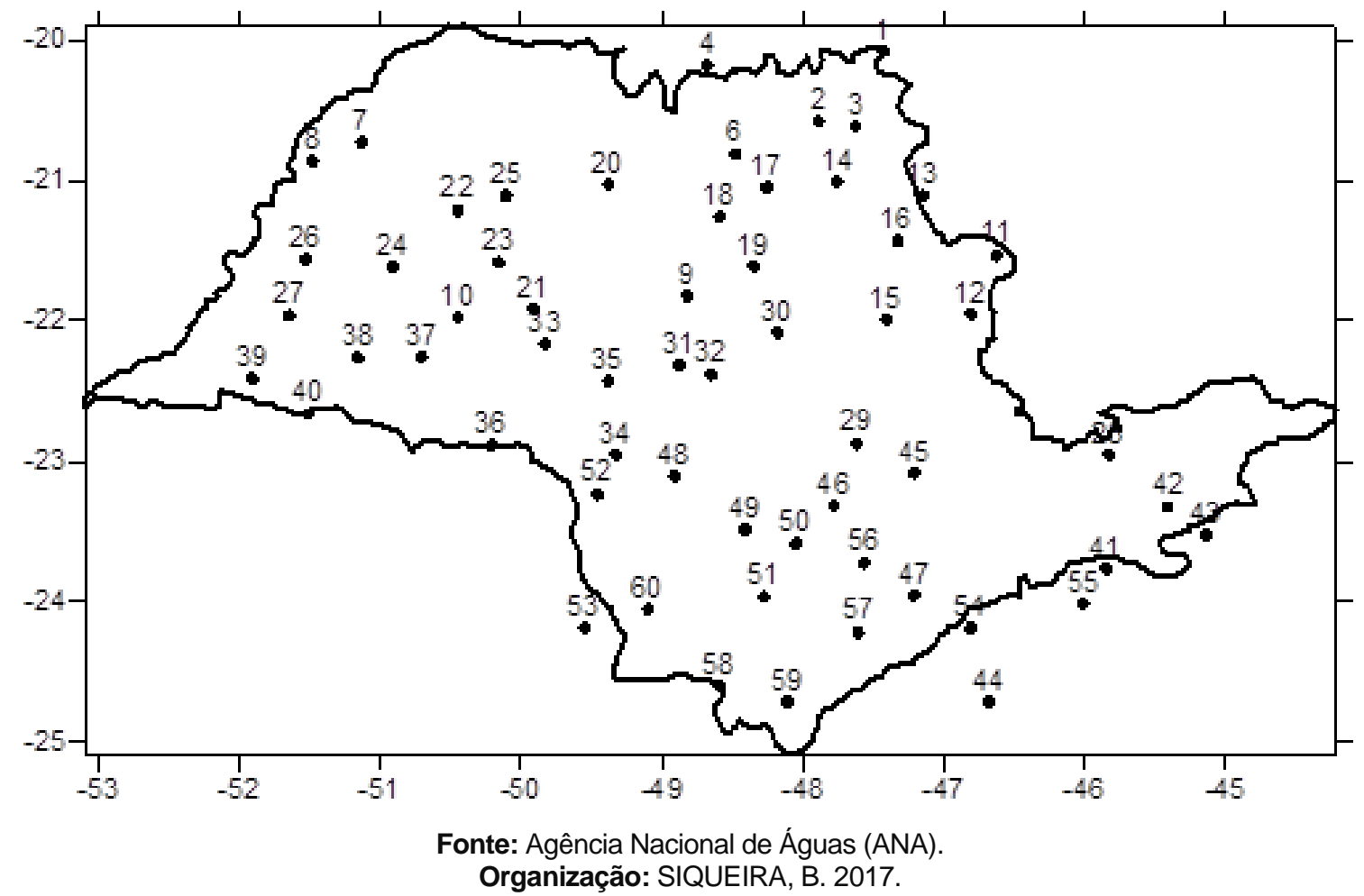

As estações foram devidamente tratadas para que os resultados não fossem comprometidos, uma ação básica quando se quer realizar uma análise climatológica. Os dados ausentes nas estações pluviométricas são substituídos por dados de estações vizinhas e, além disso, é necessário seguir o padrão de pelo menos 30 anos de análise para que a pesquisa tenha resultados finais confiáveis, sendo o clima uma série de estados atmosféricos sobre determinado lugar em sua sucessão habitual (SORRE,1934). Os dados de 
chuva foram organizados em formato diário para o Índice de Concentração (IC) e mensal para o Índice de Precipitação Concentrada (IPC). Ambos são índices estatísticos aplicados à Climatologia com o objetivo de quantificar as concentrações diárias e mensais da precipitação no estado de São Paulo. Cada um deles possui uma metodologia a ser seguida e, no caso deste estudo, foram calculados no R, um software livre.

Para o $R$ a referência básica é a Nova Linguagem S: um ambiente de programação de análise de dados e gráficos elaborado por Richard A. Becker, John M. Chambers e Allan R. Wilks, ambos do Bell Laboratories. Há agora alguns livros que descrevem como usar o R para análise de dados e estatísticas, bem como documentação para o $\mathrm{S}$ e o S-Plus, que podem ser usados juntamente com o R, mantendo as diferenças entre eles (VENABLES, 2004).

Muitas pessoas usam o R como um sistema estatístico e, sendo assim, muitas estatísticas modernas foram implementadas. Algumas delas são construídas na base $\mathrm{R}$ de desenvolvimento e outras são fornecidas como "pacotes". Existem aproximadamente 25 "pacotes" fornecidos com o R e muitos mais estão disponíveis através da família CRAN, que podem ser obtidos de sites via Internet (VENABLES, 2004).

O pacote utilizado nesta pesquisa é o Precintcon, desenvolvido por Povoa e Nery (2016), onde existem diversos parâmetros de entrada, como o objeto a ser analisado, o período que se quer trabalhar, onde deve constar o número de dias ou meses a serem agrupados durante o cálculo dos índices. Por exemplo:

precintcon.ci.per.year.analysis(d1, interval = 1), para IC;

precintcon.pci.analysis(d1), para IPC;

Após o cálculo dos índices, isolinhas de precipitação foram traçadas no Golden Surfer 13. Surfer é uma função completa de contorno e modelagem da superfície que pode ser executado no Microsoft Windows, amplamente utilizado para modelagem de terreno, modelagem batimétrica, visualização de paisagem, análise de superfície, mapeamento de contorno de bacias hidrográficas e superfícies 3D, gridding, enquadramento visual, volumetria, entre outros. Trata-se de um software utilizado por hidrólogos, engenheiros, geólogos, oceanógrafos, biólogos, geofísicos, pesquisadores médicos e climatologistas.

Através do Surfer foi possível a elaboração das isolinhas de precipitação, juntamente com o método de Krige para a interpolação dos dados. O método de Krige é um processo de estimativa por médias móveis, de valores de variáveis distribuídas no espaço a partir de valores adjacentes, enquanto considerados como interdependentes por uma função denominada variograma. Como no cálculo dessa função a somatória de diferenças ao quadrado é dividida por dois (número de pares de valores) o termo correto seria semi-variograma, porém é usual o emprego do termo variograma, por ser mais sintético (LANDIM et al. 2002).

Sobre a metodologia utilizada para calcular os índices, foi utilizado o Índice de Concentração (IC) elaborado por Javier Martin-Vide (2004), para determinar o impacto relativo que as diferentes classes de precipitação exercem na heterogeneidade da precipitação diária.

O fato é que em determinado período e local a probabilidade de pequenas quantidades diárias de precipitação é maior que grandes quantidades, ou seja, tem-se uma classe mais baixa de precipitações diárias o que interfere nas frequências absolutas, que também diminuem conforme avançam para os intervalos consecutivos (BROOKS et al. 1953; MARTIN-VIDE, 2004).

Analisando alguns trabalhos desenvolvidos sobre a temática dos índices citados, tem se os de Riehl (1949); Olascoaga (1950); Martin-Vide (2004); Zhang et al. (2009) e Coscarelli e Caloiero (2012). Os autores estudaram os percentuais acumulados de precipitação que contribuíram com as percentagens acumuladas de dias durante a ocorrência de acordo com as seguintes etapas:

1. Classificar os limites de classe de precipitação (intervalo de classe igual a $1 \mathrm{~mm}$ );

2. A contagem do número de dias, com intervalo de precipitação que caiu para cada intervalo de classes (i $=1,2, \ldots \mathrm{n}$ ) e calculando a quantidade associada de precipitação;

3. O cálculo da soma cumulativa de itens de saída: passo 2;

4. Contando as percentagens cumulativas de dias chuvosos e a quantidade associada de precipitação com base no passo 3 . 
Precipitações extremas estão associadas com inundações, portanto o estudo do índice de concentração tem méritos científicos e práticos, pois possibilita uma melhor compreensão dos eventos de inundação em uma determinada área de estudo (SHI et al. 2014).

O IC, que se assemelha ao de Gini, pode ser definido como:

IC $-S^{\prime} / 5000=\left(5000-A^{\prime}\right) / 5000$

Dessa forma, o valor de IC é a fração de S' e a área de superfície do triângulo inferior delimitada pela linha equidistribuição (MARTIN-VIDE, 2004). O Índice de Concentração indica a contribuição de precipitação extrema para certas durações de tempo.

De modo geral, segundo Javier Martin-Vide (2004), valores acima de 0,61 significam que $70 \%$ da precipitação total está dentro de $25 \%$ dos dias mais chuvosos.

O Índice de Precipitação Concentrada (IPC) foi desenvolvido por Oliver (1980) e De Luis et al. (1997) com a finalidade de quantificar a precipitação mensal e a heterogeneidade da precipitação em um ano. É um indicador na distribuição espacial e temporal da precipitação, tradicionalmente aplicado em escalas anuais. Quando o valor aumenta, significa maior concentração da precipitação.

Alterações nos valores do IPC parecem ser complexas e podem estar relacionadas com as características globais e sinóticas da atmosfera e com fatores locais que afetam as tendências da precipitação (LUIS et al. 2011).

Se o aumento da concentração de chuva ocorrer diariamente, a frequência de precipitação diária é que vai aumentar, sendo que o total anual permanece o mesmo ou aumenta com o passar do tempo. Entretanto, se a situação for contrária, ou seja, queda no valor anual de precipitação significa que a frequência diária das mesmas pode estar diminuindo.

O índice modificado é expresso por:

IPC $=100 * \sum_{\mathrm{i}=1}^{12}{ }_{\mathrm{pi}}{ }^{2} /\left(\sum_{\mathrm{i}=1}{ }^{12} \mathrm{P}_{\mathrm{i}}\right)^{2}$

Onde pi é a quantidade de chuvas do ith mês, calculado para cada um dos pluviômetros e para cada ano, durante o período de estudo. Conforme descrito por Oliver (1980), os valores de IPC anuais abaixo de 10 indicam uma distribuição de precipitação mensal uniforme, enquanto os valores entre 11 e 20 denotam sazonalidade na distribuição das chuvas. Valores acima de 20 correspondem a clima com marcada variabilidade mensal na quantidade de chuva.

O índice também pode ser calculado em escala sazonal para os meses correspondentes as estações do verão, outono, primavera e inverno (LUIS et al. 2011):

IPCsazonal $={ }^{\sum 3}{ }_{\mathrm{i}=1 \mathrm{Pi}}{ }^{2} /\left(\sum_{\mathrm{i}=1 \mathrm{Pi}}\right)^{2} .25$

Também em uma escala supra-sazonal, no período úmido, que compreende os meses de outubro a março,e seco, de abril a setembro (LUIS et al. 2011):

IPCsupra sazonal $={ }_{\mathrm{i}=1}^{\sum 6} \mathrm{Pi}^{2} /\left({ }_{\mathrm{i}=1 \mathrm{Pi}}^{\sum 6}\right)^{2} \cdot 50$ :

\section{RESULTADOS E DISCUSSÃO}

As isolinhas de precipitação foram obtidas através da interpolação dos dados de precipitação no software Golden Surfer 13. Ambas denotam significativa variabilidade da precipitação no estado de São Paulo, que pode ser explicada por diversos fatores. Um importante fator é o relevo, já que o sul do estado de São Paulo é cortado pelo Trópico de Capricórnio, o que implica em uma orografia que varia do nível do mar, na costa, a altitudes de 1000 metros, na direção Leste-Norte, aproximadamente (NERY et al. 2004).

A Figura 2 mostra a distribuição das médias anuais de precipitação para o estado de São Paulo e permite observar valores mais significativos na região do Vale do Paraíba e mais ao nordeste do referido estado, no limite com o sul de Minas Gerais, por onde passa a Serra da Mantiqueira.

A maioria dos valores são superiores a 1000 milímetros e o relevo aparece como um fator importante. A faixa litorânea, por exemplo, apresenta os valores mais significativos, superiores a 1400 milímetros por causa da influência orográfica de trechos serranos (MONTEIRO, 1973).

No sudoeste do estado, os índices elevados devem estar relacionados à latitude mais favorável à penetração de massas polares, naturalmente favorecidas topograficamente através do eixo da Bacia do rio Paraná (MONTEIRO, 1973).

\begin{tabular}{llllll}
\hline Caminhos de Geografia & Uberlândia - MG & v. 19, n.67 & Set/2018 & p. 99-108 & Página 103
\end{tabular}


Figura 2: Distribuição das médias pluviométricas anuais no estado de São Paulo, de 1970 a 2010.

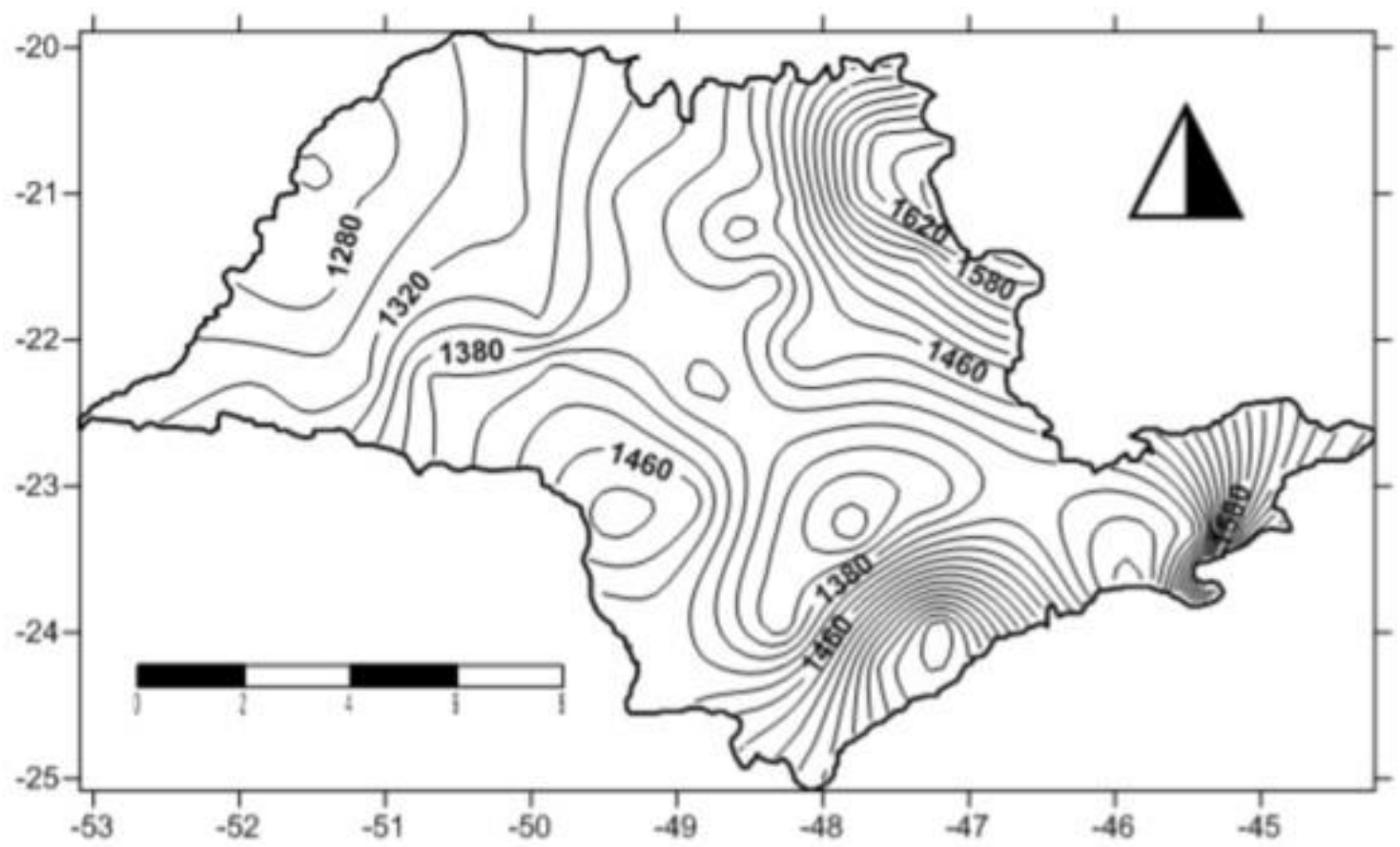

Organização: SIQUEIRA, B., 2017.

A Figura 3 mostra a concentração diária da precipitação no estado de São Paulo onde é possível observar maiores valores na região centro-sul e costeira do estado, IC entre 0,58 e 0,62. Esse fato pode ser explicado pela dinâmica das massas polares e pela advecção de ar úmido do oceano Atlântico. Além disso, a região é cortada pelo Trópico Capricórnio e, tanto o trópico quanto a massa, determinam um regime de precipitação diferenciado nesta área em relação às outras (NERY et al. 2004).

Figura 3: Índice de Concentração da precipitação no estado de São Paulo, de 1970 a 2010.

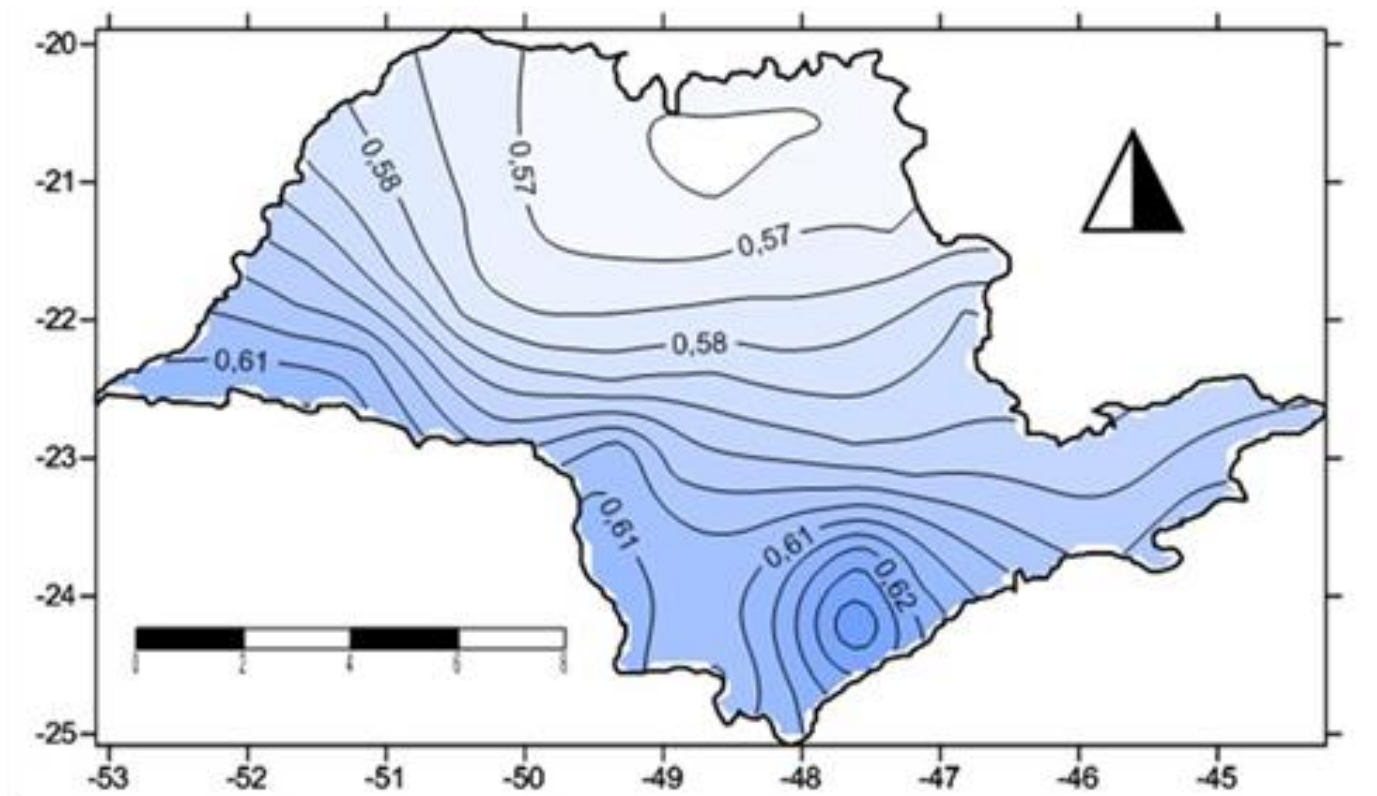

Organização: SIQUEIRA, B., 2017. 
A massa polar de maior influência no Brasil é a massa Polar marítima ( $\mathrm{mPa})$ e acha-se associada aos anticiclones migratórios que se localizam na região subantártica. Em virtude dos mecanismos de subsidência associados, essa massa é originalmente muito estável, no entanto, a medida que se desloca para o norte ou para o nordeste, a inversão desaparece e a massa passa a ser instável. Embora existam em todas as estações, são mais comuns no inverno (NERY e CARFAN, 2013).

O processo de advecção associado à dinâmica das massas polares consiste na transferência das propriedades da massa de ar, no caso a polar. Essa transferência acontece em função do campo de velocidades existentes na própria atmosfera. Na situação descrita acima, para a região centro-sul e costeira do estado de São Paulo, a massa de ar foi transportada horizontalmente para uma determinada zona em que a propriedades térmicas e graus de umidades são diferentes, ocasionando precipitação intensa. Segundo Monteiro (1973), o Litoral Sul apresenta um crescente aumento de participação das massas polares segundo o aumento das latitudes e um teor de pluviosidade bem mais elevado que o setor norte, no entanto, esse elevado teor de pluviosidade segue, antes de mais nada, a disposição do relevo e orientação da costa em relação às correntes de circulação atmosférica regional.

Levando em consideração a classificação de Martin-Vide (2004), essa área do estado de São Paulo, com IC $=0,62$ apresenta $70 \%$ da precipitação concentrados em $25 \%$ dos dias mais chuvosos, indicando chuvas intensas e severas em poucos dias ao longo do ano.

Essa porção do estado, onde o IC atinge valor igual a 0,62, abriga a Região Metropolitana de São Paulo, com aproximadamente 22 milhões de habitantes desenvolvendo diversas atividades econômicas, sociais, políticas e culturais. As regiões metropolitanas foram criadas no Brasil ao longo das últimas décadas em função do crescimento significativo da população. O processo de urbanização acelerado ocorreu após os anos 60 , gerando uma população urbana praticamente sem infraestrutura, principalmente na década de 80 , quando os investimentos foram reduzidos (TUCCI, 1995).

Os efeitos da urbanização fazem-se sentir sobre todo o aparelhamento urbano relativo a recursos hídricos: abastecimento de água, transporte e tratamento de esgotos cloacais e drenagem pluvial. As enchentes urbanas constituem-se num dos principais impactos sobre a sociedade e que podem ocorrer devido à urbanização ou à inundação natural da várzea ribeirinha (TUCCI, 1995).

O desenvolvimento urbano propicia a impermeabilização do solo através de telhados, ruas, calçadas e assim, a parcela da água que infiltrava passa a escoar pelos condutos, aumentando o escoamento superficial. O volume que escoava lentamente pela superfície do solo e ficava retido pelas plantas, com a urbanização, passa a escoar no canal, exigindo maior capacidade de escoamento das seções (TUCCI, 1995). As demais áreas do estado apresentaram valores médios de concentração diária da precipitação entre 0,58 e 0,57 , pois estão sob a influência da continentalidade, das massas de ar polares, orografia e por ser uma área de transição de sistemas convectivos e frentes frias, especialmente na primavera e no verão (NERY et al. 2004).

As frentes são uma zona de transição ou superfície de contato entre duas massas de ar de densidades diferentes, o que normalmente implica temperaturas diferentes também. Por exemplo, a zona de convergência entre calor, ar úmido e frio e ar seco (NERY e CARFAN, 2013).

Quando a frente é fria, o frio seco, mais denso, empurra a massa quente e a leva para cima. A passagem de uma frente fria pode acarretar em chuvas intensas, se houver a umidade necessária. A continentalidade associada à orografia são dois fatores responsáveis pela menor quantidade de umidade nessa área do estado e consequente menor concentração de chuva.

A Figura 4 revela a concentração mensal da precipitação no estado de São Paulo, estimada através do IPC e onde é possível observar que as menores concentrações estão na região centro-sul e costeira do estado, em contraste com a concentração diária. Está concentração mensal e diária inversas no mesmo local está relacionada à influência da massa Tropical continental, principalmente no verão e às massas polares quando associadas a este fluxo (NERY et al. 2004).

A massa Tropical continental $(\mathrm{mPa})$ está associada à baixa pressão predominante sobre a região do Chaco (na América do Sul), em consequência do grande aquecimento da superfície, especialmente no verão. Esse superaquecimento continental dá origem a uma massa quente, seca e instável, apresentando intensa atividade convectiva. Entretanto, as precipitações associadas à atuação da $\mathrm{mPa}$ são fracas, predominando céu claro e pouco nublado, o que favorece o aquecimento diurno e o resfriamento noturno (NERY e CARFAN, 2013).

A baixa concentração mensal da precipitação no centro-sul do estado também está associada ao processo de urbanização. Nos últimos anos, o regime das chuvas, especialmente em áreas extremamente

\begin{tabular}{llllll}
\hline Caminhos de Geografia & Uberlândia - MG & v. 19, n. 67 & Set/2018 & p. 99-108 & Página 105
\end{tabular}


urbanizadas como o referido estado, tem sido alterado por condições adversas de temperatura associadas à emissão de gases do efeito estufa. Hoje, as chuvas intensas e severas tendem se concentrar em poucos dias ao longo do mês, especialmente na estação do verão, quando as temperaturas, já altas, elevam-se ainda mais por causa da emissão de gases, do estabelecimento de ilhas de calor e impermeabilização do solo (TUCCI, 1995; NUNES, 2009b; NUNES, 2015). A urbanização merece grande enfoque na evolução dos processos de transformação do espaço acarretando em mudanças climáticas de origem antropogênica, que infelizmente, contribuem para o advento de inundações e deslizamentos de terra, por exemplo.

Figura 4: Índice de Precipitação Concentrada da precipitação no estado de São Paulo, de 1970 a 2010.

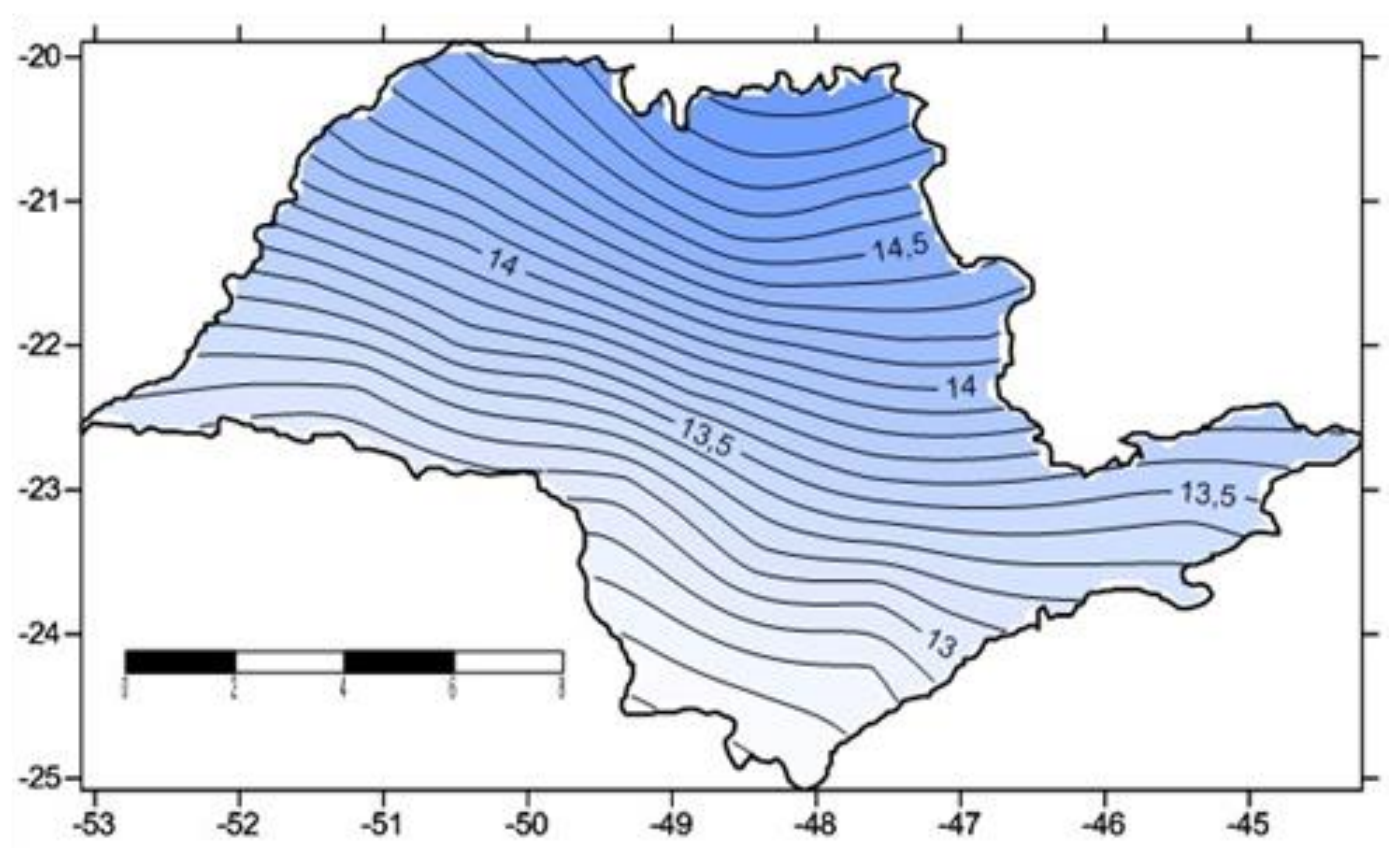

Organização: SIQUEIRA, B., 2017.

O clássico estudo desenvolvido por Dettwiller (1970) sobre as relações entre a urbanização e o clima da cidade de Paris, evidenciou que o crescimento dos assentamentos urbanos e da industrialização poderia ter induzido a um aumento das precipitações na cidade em aproximadamente $10 \%$, sendo que parte desse percentual era referente a atividades industriais.

O aumento das precipitações nas áreas urbanas pode ser inferido a maior rugosidade das superfícies construídas associada a um aumento da turbulência, ao aquecimento, causa da formação de correntes ascendentes e aos níveis de poluição urbana que acarretam em maiores acúmulos de núcleos higroscópios de condensação (LANDSBERG, 1981).

Sobre o processo de urbanização e o aumento da precipitação, é importante mencionar a influência de fenômenos meteorológicos como O El Niño e a Zona de Convergência do Atlântico Sul (ZCAS), que atuam sobre o estado de São Paulo em determinados períodos do ano.

O El Niño provoca alterações significativas de curta duração (12 a 18 meses) na distribuição da temperatura da superfície da água do Oceano Pacífico, com profundos efeitos no clima. Quando acontece um El Niño, que ocorre irregularmente em intervalos de 2 a 7 anos, com uma média de 3 a 4 anos, os ventos sopram com menos força em todo o centro do Oceano Pacífico, resultando em uma diminuição da ressurgência de águas profundas e na acumulação de água mais quente que o normal na costa oeste da América do Sul, além de uma alteração climática em todo o Pacífico Equatorial: as massas de ar quentes e úmidas acompanham a água mais quente, provocando chuvas excepcionais na costa oeste da América do Sul e secas na Indonésia e na Austrália (NERY e CARFAN, 2013).

O principal efeito desse aquecimento no Sudeste do Brasil é manter as temperaturas mais altas que o normal. No verão, as temperaturas mais altas propiciam a ocorrência de temporais, que podem se intensificar com os efeitos da urbanização nas grandes cidades.

\begin{tabular}{llllll}
\hline Caminhos de Geografia & Uberlândia - MG & v. 19, n. 67 & Set/2018 & p. 99-108 & Página 106
\end{tabular}


A ZCAS se posiciona na orientação noroeste-sudeste e estende-se desde sul da região Amazônica até a região central do Atlântico Sul (SILVA DIAS et al. 1988). É o principal sistema de grande escala responsável pelo regime de chuvas do Sul e Sudeste do Brasil, durante os meses da primavera e do verão e de significativa importância no processo de transferência de calor, momento e umidade dos trópicos para as latitudes mais altas.

Os eventos de enchentes e inundações que acontecem na estação do verão, especialmente nas grandes cidades como São Paulo, estão associados à ZCAS e sua permanência por prolongados períodos sobre o Sudeste do país.

O estado de São Paulo apresenta muitas potencialidades, seja no âmbito agrícola, industrial ou energético, atividades que dependem intrinsicamente da disponibilidade de água. A rápida desordenada ocupação do território paulista, associada às sua potencialidade e ao regime de chuvas pode trazer á tona situações que acarretem rupturas nas funcionalidades territoriais, especialmente no período chuvoso, concentrado na estação do verão, quando eventos catastróficos podem ocorrer.

\section{CONSIDERAÇÕES FINAIS}

Os índices se mostraram ferramentas consistentes na quantificação da precipitação na área de estudo e possibilitaram uma estimativa sólida e eficaz a respeito da variabilidade da mesma.

O conhecimento da dinâmica climática atuante na área de estudo e sua posterior associação com a concentração da precipitação nas distintas regiões do estado se deram de maneira condizente e permitiram uma reflexão sobre o processo de urbanização, um dos responsáveis pelas mudanças no regime da precipitação, especialmente no que tange à intensidade e frequência.

O centro e extremo-sul do estado foram as áreas de maior concentração diária e menor concentração mensal. Esse contraste se dá pela influência de sistemas sinóticos importantes, como as massas polares e a massa Tropical Continental, além da advecção de ar úmido e intensa urbanização que vem sofrendo nos últimos anos.

O estado apresenta suscetibilidades e potencialidades distintas e vem sendo ocupado de forma rápida e deletéria, fator que contribui para o advento de desestruturações de todas as ordens, que se consubstanciam, via de regra, em desastres naturais (NUNES, 2015) especialmente os hidrológicos, em sua maioria na estação do verão, nos grandes centros urbanos do mundo, como a cidade de São Paulo.

\section{REFERÊNCIAS}

ANA. Agência Nacional de Águas. Disponível em: <http://www.ana.gov.br>. Acesso em: 23 de agosto de 2017.

BROOKS, C. E. P.; CARRUTHERS, N. Ernest Pelham et al. Handbook of statistical methods in meteorology. London: Stationery Office, p. 162-165, 1953. Handbook of statistical methods in meteorology. 1953.

COSCARELLI, R.; CALOIERO, T. Analysis of daily and monthly rainfall concentration in Southern Italy (Calabria region). Journal of Hydrology, v. 416, p. 145-156, 2012. https://doi.org/10.1016/i.jhydrol.2011.11.047

DE LUIS, M. et al. Distribución espacial de la concentración y agresividad de la lluvia en el territorio de la Comunidad Valenciana. Cuaternario y Geomorfología, v. 11, n. 3-4, p. 33-44, 1997.

DETTWILLER, Jacques. Évolution séculaire du climat de Paris: influence de l'urbanisation. Dir. de la Météorologie Nationale, 1970.

FERNANDES, K. A.; SATYAMURTY, P.rakki. Cavados invertidos na região central da América do Sul. In: Congresso Brasileiro de Meteorologia. 1994. p. 93-94, $1994 .$.

Golden Software. Disponível em: <http://www.goldensoftware.com/products/surfer>. Acesso em: 01 de setembro de 2017.

IBGE. - Instituto Brasileiro de Geografia e Estatística. Cidades@. Disponível em: $<$ http://cidades.ibge.gov.br/xtras/home.php $>$. Acesso em: 01 de setembro de 2017. 
LANDIM, P. M. B.; STURARO, J. R. Krigagem indicativa aplicada à elaboração de mapas probabilísticos de riscos. Rio Claro: DGA, 2002.

LANDSBERG HE. City climate. In: General Climatology, 3, Landsberg HE (ed.). New York: Elsevier Scientific, 1981.

LUIS, M. de; HIDALGO, J. C. G.e et al. Precipitation concentration changes in Spain 1946-2005. Natural Hazards and Earth System Science, v. 11, n. 5, p. 1259-1265, 2011. https://doi.org/10.5194/nhess-11$\underline{1259-2011}$

MARTIN-VIDE, J. Spatial distribution of a daily precipitation concentration index in peninsular Spain. International Journal of Climatology, v. 24, n. 8, p. 959-971, 2004. https://doi.org/10.1002/joc.1030

MONTEIRO, C. A. F., 1973. A dinâmica climática e as chuvas no Estado de São Paulo: Estudo geográfico sob a forma de atlas. Universidade de São Paulo, Inst. Geografia. 129 p.

NERY, J. T. SILVA, E. S.; CARFAN, A. C. Distribuição da precipitação pluvial no Estado de São Paulo. VI Simpósio Brasileiro de Climatologia Geográfica, v. 6, 2004.

NERY, J.T.; CARFAN, A. C. Glossário de termos técnicos em meteorologia e climatologia. Jundiaí: Ed. Paco Editorial, 2013.

NIMER, E. Climatologia do Brasil. Secretaria de Planejamento e Coordenação da Presidência da República e IBGE, Rio de Janeiro, 1989, 421 p.

NUNES, L. H. Compreensões e ações frente aos padrões espaciais e temporais de riscos e desastres. Revista Territorium n. 16, 2009b. pp. 179-189.

NUNES, L. H.; VICENTE, A. K.; CANDIDO, D. H. Clima da região Sudeste do Brasil. Tempo e Clima no Brasil. Oficina de Textos, São Paulo, p. 243-258, 2009a.

NUNES, Lucí Hidalgo. Urbanização e desastres naturais. São Paulo: Ed. Oficina de Textos, 2015.

OLASCOAGA, M. J. Some aspects of Argentine rainfall. Tellus, v. 2, n. 4, p. 312-318, 1950. https://doi.org/10.3402/tellusa.v2i4.8601

OLIVER, J. E. Monthly precipitation distribution: a comparative index. The Professional Geographer, v. 32, n. 3, p. 300-309, 1980. https://doi.org/10.1111/1.0033-0124.1980.00300.x

POVOA, L. V., NERY, J. T. Manual do usuário do pacote Precintcon. Laboratório Computacional da Universidade Estadual Paulista, campus de Ourinhos, 2016.

RIEHL, Herbert. Some aspects of Hawaiian rainfall. Bulletin of the American Meteorological Society, v. 30, n. 5, p. 176-187, 1949. https://doi.org/10.1175/1520-0477-30.5.176

$\mathrm{SHI}$, Peng et al. Spatial distribution and temporal trends in daily and monthly precipitation concentration indices in the upper reaches of the Huai River, China. Stochastic Environmental Research and Risk Assessment, v. 28, n. 2, p. 201-212, 2014. https://doi.org/10.1007/s00477-013-0740-z

SILVA DIAS, P. L.; CAPLAN, P.; KOUSKY, E. V. As chuvas intensas de fevereiro de 1988: circulação global e previsibilidade. In: Congresso Brasileiro de Meteorologia, 1988. 1988. p. 6-10.

SORRE, M. Traité de climatologie biologique et médicale. Paris: Piery Masson et Cie Éditeurs, p.1-9, 1934.

TUCCI, C. E. M. Inundações Urbanas. In: TUCCI, C. E. M.; PORTO, R. L. \& BARROS, M. T (org.)

Drenagem Urbana. Porto Alegre: Editora da Universidade, 1995, p. 15-36.

VENABLES, William N. et al. An introduction to R. 2004.

ZHANG, Qiang et al. Changing properties of precipitation concentration in the Pearl River basin, China.

Stochastic Environmental Research and Risk Assessment, v. 23, n. 3, p. 377-385, 2009.

Recebido em: 07/09/2017

Aceito para publicação em: 20/04/2018 